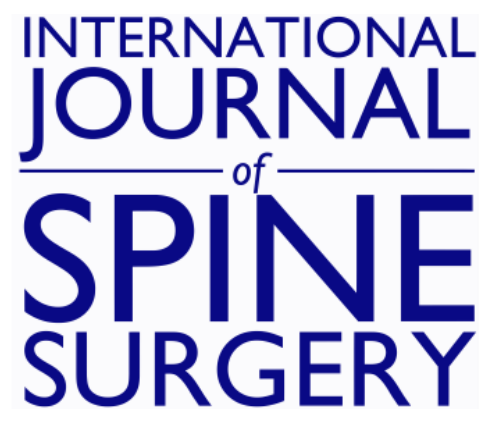

\title{
Low Complication Rate of Anterior Lumbar Spine Surgery in an Ambulatory Surgery Center
}

\author{
JASON M. CUÉLLAR, WILLIS WAGNER and ALEXANDRE RASOULI
}

Int J Spine Surg 2020, 14 (5) 687-693

doi: https://doi.org/10.14444/7100

http://ijssurgery.com/content/14/5/687

This information is current as of April 26, 2023.

Email Alerts Receive free email-alerts when new articles cite this article. Sign up at:

http://ijssurgery.com/alerts 


\title{
Low Complication Rate of Anterior Lumbar Spine Surgery in an Ambulatory Surgery Center
}

\author{
JASON M. CUÉLLAR, MD, PHD, ${ }^{1,2}$ WILLIS WAGNER, MD ${ }^{3}$ ALEXANDRE RASOULI, MD ${ }^{1,2}$ \\ ${ }^{I}$ Cedars-Sinai Spine Center, ${ }^{2}$ Department of Orthopaedic Surgery, ${ }^{3}$ Division of Vascular Surgery, Cedars-Sinai Medical Center, Los Angeles, California
}

\begin{abstract}
Background: As healthcare costs rise, attempts are being made to perform an increasing proportion of spine surgery in ambulatory surgery centers (ASCs). ASCs are more efficient, both economically and functionally. There remains uncertainty regarding the safety of performing anterior lumbar procedures requiring vascular access, as little has been published on this subset of patients.

Methods: This is a consecutive case series analysis of anterior lumbar spine surgeries that were performed in a freestanding ASC in a private-practice setting over a 1-year period, including anterior lumbar interbody fusion, artificial disc replacement, and hybrid procedures. The preoperative, intraoperative, and postoperative data recorded included age, gender, body mass index, tobacco use, and the presence of diabetes; level and procedure, operating room time, estimated blood loss, complications; discharge site, occurrence of reoperation, hospital admission, or any medical complication or infection over a 90-day period.

Results: Fifty-one patients underwent 63 treated levels (34 artificial disc replacement, 29 anterior lumbar interbody fusion): 40 single-level, 10 two-level, one three-level. Average age was 45 years; 27 female, 24 males. None of the patients were diabetics, three were current smokers, seven were former smokers. Average body mass index was $27 \pm$ 4 (range 16-36). Average total anesthesia time was 100 minutes (range 57-187 minutes). Average estimated blood loss was $23 \mathrm{~mL}$ (range $5-250 \mathrm{~mL}$ ). Seventy-one percent of patients were discharged directly home, $29 \%$ to an aftercare facility. In the 30-day postoperative period there were no deaths, one hospital admission for pain, and no significant medical complications or surgical site infections.

Conclusion: In this consecutive case series artificial disc replacement or anterior lumbar interbody fusion was performed at 63 levels in 51 patients in the ASC setting with an observed major complication rate of zero and hospital unplanned admission rate of $2 \%(1 / 51)$. This provides some evidence that these procedures are safe to perform in the ASC setting. However, a highly experienced vascular surgeon and efficient surgical team, and strict patient selection criteria are all critical in making this possible.
\end{abstract}

Lumbar Spine

Keywords: ambulatory surgery center, anterior lumbar discectomy, anterior lumbar interbody fusion, lumbar disc replacement, outpatient spine surgery

\section{INTRODUCTION}

As the cost of healthcare has been rising rapidly within the United States, an attempt is being made to perform an increasing proportion of spine surgery procedures in ambulatory surgery centers (ASCs). ASCs are more efficient than large hospitals, both economically and functionally, with reports of high rates of safety, economic efficiency, and patient satisfaction for outpatient anterior cervical discectomy and fusion, ${ }^{1-14}$ posterior cervical foraminotomy, ${ }^{15,16}$ cervical total disc replacement, ${ }^{17,18}$ posterior lumbar laminectomy or discectomy, ${ }^{19-25}$ posterior lumbar fusion (minimally invasive transforaminal lumbar interbody fu- sion), ${ }^{26,27}$ and lumbar direct lateral interbody fusions. ${ }^{28,29}$

There has been uncertainty regarding the safety of performing anterior lumbar procedures requiring vascular access, as to date little has been published on this subset of patients. The current study analyzes the safety of one-, two- and three-level anterior lumbar interbody fusions (ALIFs) and anterior lumbar artificial disc replacements (ADR) at levels L3 through S1 in an ASC over a one-year period.

\section{METHODS}

This is a consecutive-patient case series providing an analysis of all the anterior lumbar spine surgeries 
that the first and senior authors performed in a freestanding ASC over a one-year period, including 90 days of postoperative follow-up. Institutional review board approval was obtained (Western IRB, Olympia, Washington). Although the ASC is freestanding (not attached to a hospital), an academic medical center (level-1 trauma center) is within a two-mile radius if transfer is necessary. These spine surgeons are in private practice but perform most of their operations at the academic medical center. Procedures included in this study were ALIF and anterior lumbar discectomy and ADR. The anterior approach to the lumbar spine was performed by a vascular access surgeon with substantial experience. The vascular surgeon remained in the room during the entire procedure. The technique is described here.

\section{Anterior Spine Exposure Surgical Technique}

The exposure used a midline fascial incision. For exposures at L5-S1, a transverse skin incision was used, approximately one-third the distance between the pubis and the umbilicus. For all levels above L5$\mathrm{S} 1$, a midline skin incision was made. A left retroperitoneal approach was used unless the index level was L5-S1 and there was a high likelihood of needing future anterior spine exposure, in which case the right side was used. The transversalis fascia was incised laterally as it attaches to the abdominal wall. Middle sacral and segmental vessels were divided with hemostatic metallic clips. For exposure at L4-5 and usually at L3-4, the left iliolumbar branch of the iliac vein was divided. If this branch was large or very short, a stick-tie with a 4-0 nonabsorbable monofilament suture on the medial side was used to prevent loss of control with stretching of the common iliac vein. Exposure of L4-5 and above involved division of branches and retraction of the aorta and left iliac artery and vein to the right of the midline. Lymphatic-bearing tissue crossing the iliac vessels and lateral to the aorta was carefully divided between hemastatic clips to prevent postoperative lymphatic collections. A sponge stick was used to mobilize the peritoneum away from the abdominal wall as this is less likely to cause a peritoneal injury than a finger. Large peritoneal defects were usually closed with interrupted 3-0 absorbable sutures at the completion of the spine reconstruction. Either an Omni (Gadelius Medical, Tokyo, Japan) or a Thompson (Thompson Surgical Instruments, Traverse City, Michigan) self-retaining retractor was used to maintain the exposure. There were no revision anterior operations performed in this outpatient series.

All patients saw the vascular access surgeon in consultation in his office before the surgery. During that visit, the patient was evaluated and examined, all risks of the operation were discussed, and questions answered. A preoperative bowel preparation regimen was not used.

For fusions a small or medium BMP-2 sponge was used with corticocancellous bone chips and demineralized bone putty within a PEEK cage with two or four screws (Synfix, Depuy-Synthes, Raynham, Massachusetts). No bone marrow aspirate or other autologous product was used. For disc replacements, ProDisc was used in all cases (Centinel, West Chester, Pennsylvania).

Anesthesia was provided by a team of certified registered nurse anesthetists that are highly experienced, performing the anesthesia for approximately 10 to 20 spine surgeries per week in an ASC. General anesthesia was routinely induced with intravenous propofol and maintained with an inhaled anesthetic via endrotracheal intubation. Noninvasive blood pressure monitoring was used. Prior to incision, intravenous antibiotics and $10 \mathrm{mg}$ of dexamethasone were given. A scopalamine patch was also often administered to prevent postoperative nausea. A Foley catheter was usually not inserted. A cell-saver system was used for all cases involving levels above L5-S1 and was on stand-by for single-level L5-S1 cases.

A preoperative or postoperative ultrasoundguided local anesthetic injection ("tap block") using a long-acting agent such as bupivacaine liposomal injectable suspension was routinely given at the end of the operation. This often achieves more than 24 hours of complete or near complete peri-incisional and abdominal pain relief. Patients were monitored in the recovery room by the nursing and certified registered nurse anesthetist staff for an average of three hours. Patients were required to be ambulatory with pain controlled, void, and to tolerate oral intake prior to discharge. Mechanical prophylaxis for deep venous thrombosis was used during the intraoperative and postoperative recovery room period. No chemical anticoagulation was used. Appropriate narcotic pain medications were given as needed, such as hydrocodone-acetaminophen, oxycodone-acetaminophen, or a muscle relaxant such as methocarbamol or carisoprodol. Patients 


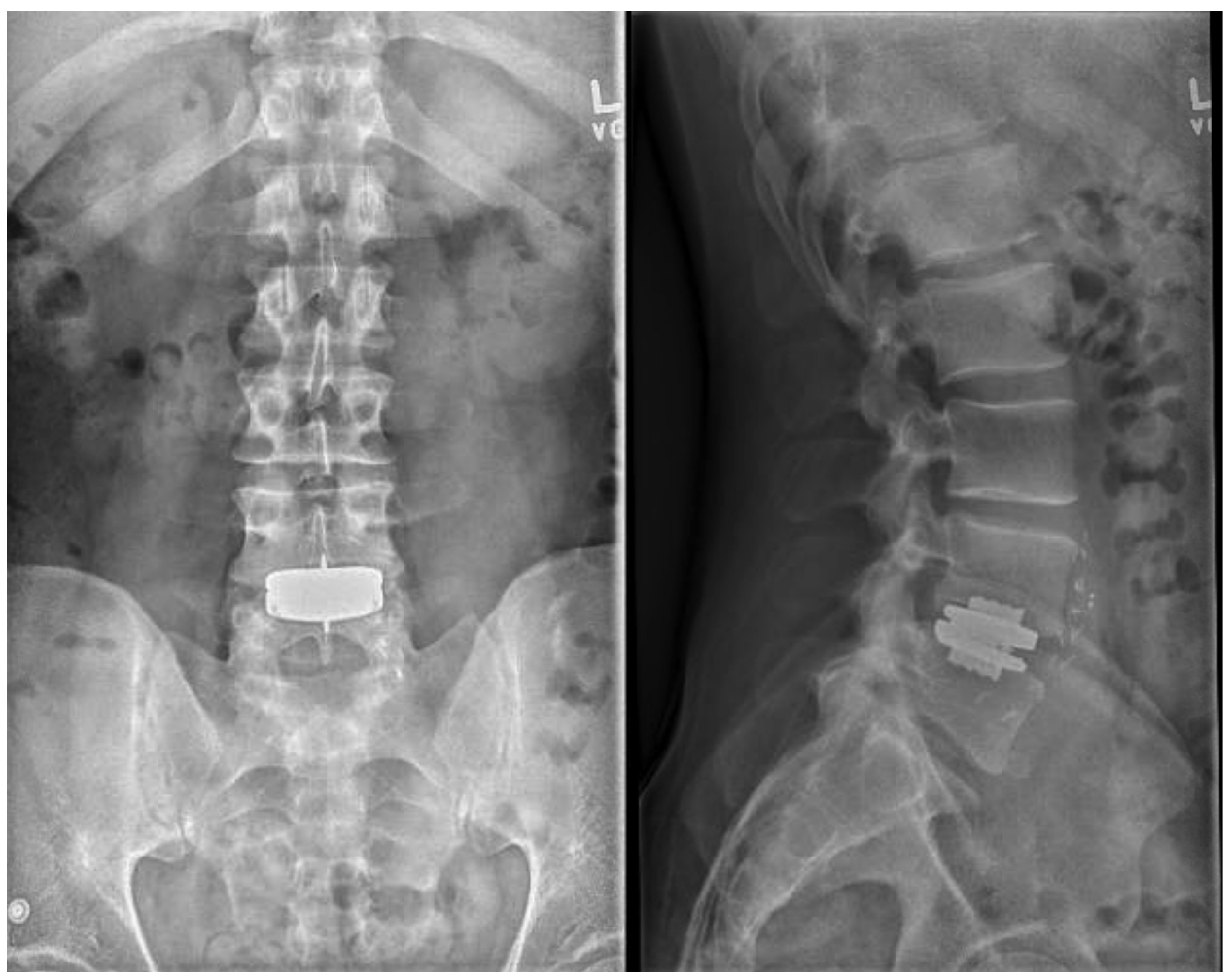

Figure 1. Case example 1. Standing postoperative lumbar spine x-ray of a 29-year-old male following a single-level artificial disc replacement at L4-5 performed in an ambulatory surgery center.

were allowed to take anti-inflammatory medications such as ibuprofen or naprosyn starting on postoperative day 1 in ADR cases. A stool softener such as Colace $100 \mathrm{mg}$ daily or twice daily was recommended for patients with a history of narcotic pain medication or requiring more than $10 \mathrm{mg}$ hydrocodone or oxycodone every 6 hours. An adjustable rigid lumbosacral orthosis was usually given to wear during ambulation for the first several weeks to restrict flexion.

The following preoperative demographic and health information was recorded: age, gender, body mass index (BMI), tobacco use, and the presence of insulin-dependent diabetes. Patient selection is critical to successfully performing these procedures in the outpatient setting, and therefore patients that had minimal medical comorbidities and with a BMI less than 30 in general were selected. The BMI cutoff was not strictly set at 30 , as patient body habitus and overall physiological health was taken into consideration.

Intraoperative data collected included level and procedure, total anesthesia time (intubation to extubation), estimated blood loss, and any complication. A cell-saver blood recirculation system was available for all procedures and was used for all multilevel cases and operations above L5-S1. For operations at the L5-S1 level it was available on standby. Data were collected from operative reports and anesthesia charts. Postoperative data collected included discharge site, the occurrence of reoperation, hospital admission, or any medical complication or infection over a 90-day period. These data were collected from the electronic medical record. In addition, a member from the anesthesia team and/or a nurse routinely called each patient on postoperative day 1 and kept records of any issues and intervention if needed.

\section{RESULTS}

Fifty-one patients underwent 63 levels of treatment: 40 at a single level, 10 at two levels, one at three levels. Of the 63 levels treated, 34 were ADR and 29 were ALIF procedures. Figures 1 to 4 provide postoperative radiographs of four case examples (Table 1). The average age was 45 years in a ratio of 27 female: 24 males. None of the patients had diabetes that required control by insulin, three were current smokers, seven were former smokers. The average BMI was $27 \pm 4$ (range 16-36). The average total anesthesia time for all cases was $100 \pm 30$ minutes (range 57-187 


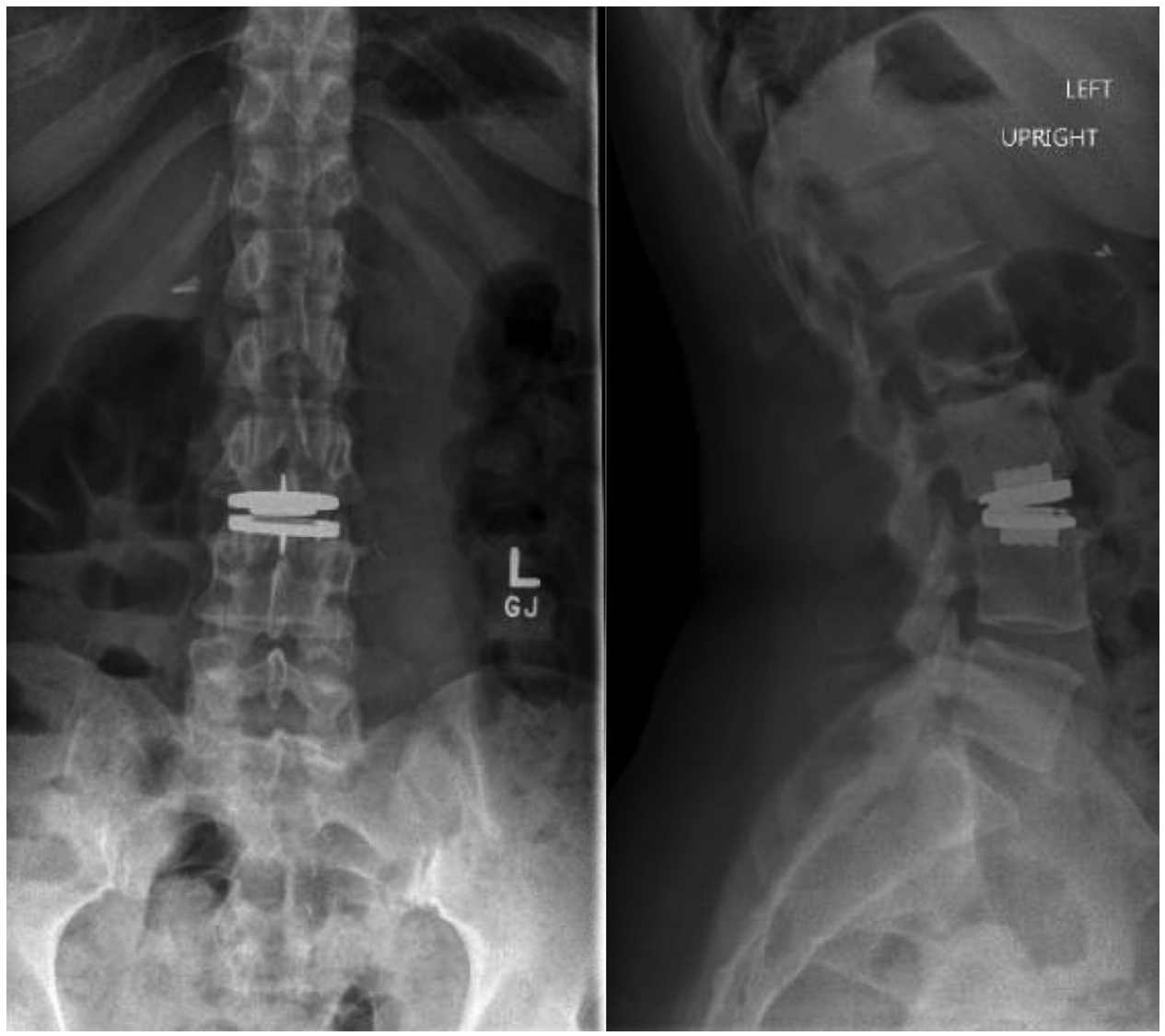

Figure 2. Case example 2. Standing postoperative lumbar spine $\mathrm{x}$-ray of a 48-year-old female following a single-level artificial disc replacement at L3-4 performed in an ambulatory surgery center.

minutes). The average estimated blood loss was 23 $\pm 35 \mathrm{~mL}$ (range 5-250 mL). For single-level cases the average total anesthesia time and estimated blood loss were $96 \pm 28$ (range 57-168) minutes and $18 \pm 11(5-250) \mathrm{mL}$, respectively. For multilevel cases the average total anesthesia time and estimated blood loss were $122 \pm 37(86-187)$ minutes and 47 \pm 78 (5-250) $\mathrm{mL}$, respectively (Table 2). Seventyone percent of patients were discharged directly home, $29 \%$ to an aftercare facility (hotel with a nurse). In the 30-day postoperative period there were zero deaths, medical complications, or surgical site infections. There was one unplanned hospital admission in a patient that complained of abdom-

Table 1. Demographic information for patients undergoing outpatient anterior lumbar procedures.

\begin{tabular}{lc}
\hline Characteristic & Statistic \\
\hline No. of patients & 51 \\
Levels treated surgically & 63 \\
Age, mean \pm SD & $45 \pm 12$ \\
Female, n $(\%)$ & $27(53)$ \\
Body mass index, mean \pm SD & $27 \pm 4$ \\
Smokers: current/former & $3 / 7$ \\
Diabetes requiring glucose control with insulin & 0 \\
\hline
\end{tabular}

inal pain the night of discharge from the ASC. The patient was a healthy 30 -year-old that underwent an uncomplicated ADR at L5-S1 and was discharged to his home on postoperative day 0 . The patient presented to an outside hospital emergency room complaining of urinary retention, near-syncopal episodes, and abdominal pain. The patient was transferred to our medical center and admitted for evaluation and observation. Serial laboratory tests demonstrated a stable hematocrit and hemoglobin; computed tomography (CT) of the abdomen and pelvis was performed. The CT demonstrated only a small retroperitoneal fluid collection; the patient was monitored overnight and discharged home the following day. This patient had a BMI of 24.4, no past medical history, and a past surgical history of an unknown procedure for splenic trauma distant to the total disc replacement surgical field.

\section{DISCUSSION}

Although we are confident that other spine surgeons are also performing anterior lumbar surgical procedures in the outpatient setting, we 


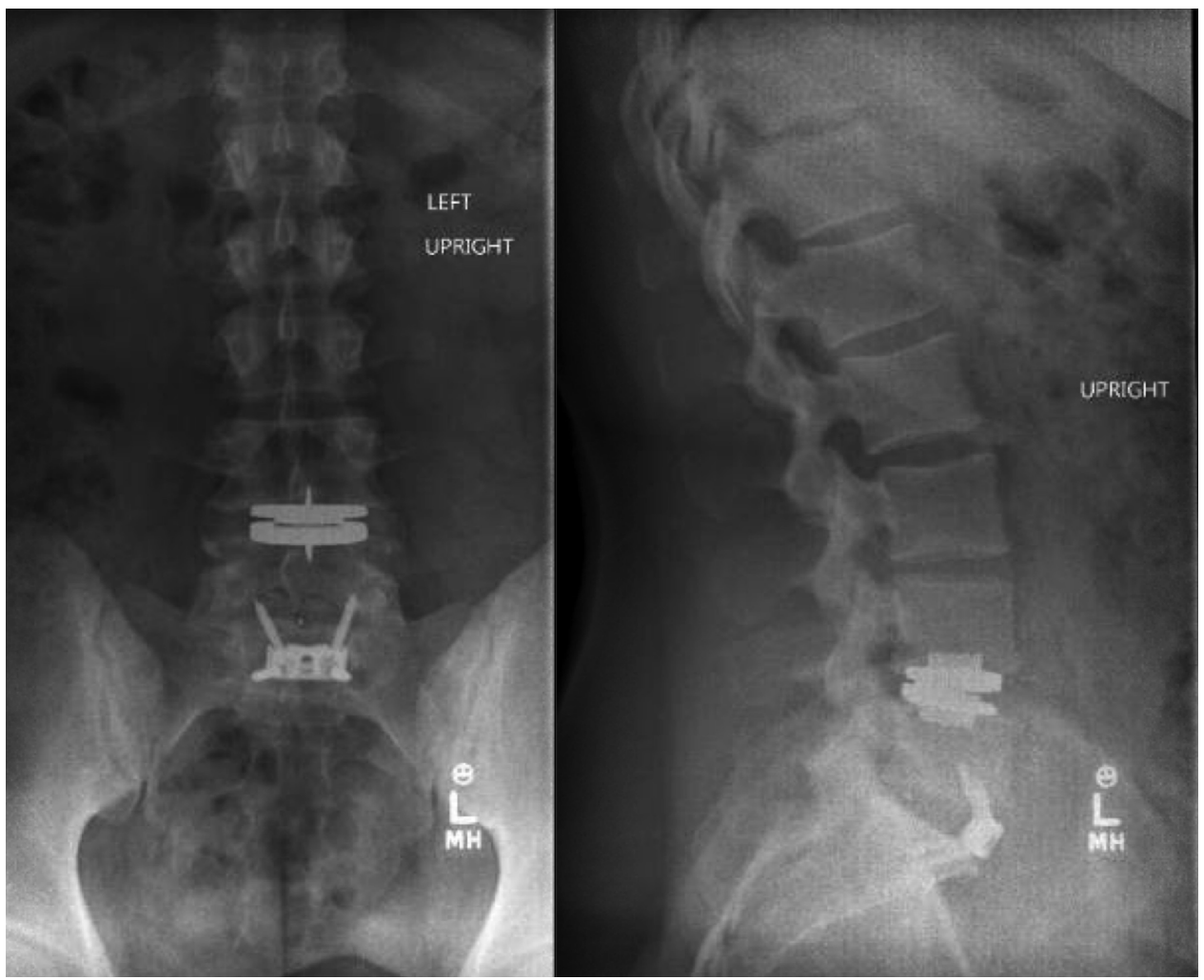

Figure 3. Case example 3. Standing postoperative lumbar spine x-ray of a 35-year-old male following an artificial disc replacement at L4-5 and simultaneous anterior lumbar interbody fusion at L5-S1 (hybrid procedure) performed in an ambulatory surgery center.

are not aware of other published studies reporting the safety and/or outcomes of this subset of patients. There is a significant body of literature reporting on the safety of other spine procedures

Table 2. Surgical parameters.

\begin{tabular}{|c|c|}
\hline Parameter & Value \\
\hline Levels treated & 63 \\
\hline L5-S1 & 34 \\
\hline L4-5 & 21 \\
\hline $\mathrm{L} 3-4$ & 7 \\
\hline Single-level & 40 \\
\hline 2-level & 10 \\
\hline 3-level & 1 \\
\hline Artificial disc replacements & 34 \\
\hline Anterior lumbar interbody fusion & 29 \\
\hline $\begin{array}{l}\text { Overall total anesthesia time, } \\
\text { mean } \pm \mathrm{SD} \text { (range), min }\end{array}$ & $100 \pm 30(57-187)$ \\
\hline $\begin{array}{l}\text { Total anesthesia time for single level, } \\
\text { mean } \pm \mathrm{SD} \text { (range), min }\end{array}$ & $96 \pm 28(57-168)$ \\
\hline $\begin{array}{l}\text { Total anesthesia time for } 2 \text { or } 3 \text { levels, } \\
\text { mean } \pm \text { SD (range), min }\end{array}$ & $122 \pm 37(86-187)$ \\
\hline $\begin{array}{l}\text { Overall estimated blood loss, } \\
\text { mean } \pm \mathrm{SD} \text { (range) } \mathrm{mL}\end{array}$ & $23 \pm 35(5-250)$ \\
\hline $\begin{array}{l}\text { Estimated blood loss for single level, } \\
\text { mean } \pm \mathrm{SD} \text { (range), } \mathrm{mL}\end{array}$ & $18 \pm 11(5-50)$ \\
\hline $\begin{array}{l}\text { Estimated blood loss for } 2 \text { or } 3 \text { levels, } \\
\text { mean } \pm \mathrm{SD} \text { (range), } \mathrm{mL}\end{array}$ & $47 \pm 78(5-250)$ \\
\hline Intraoperative complication & 0 \\
\hline Postoperative complication & 0 \\
\hline Unplanned hospital admission, n (\%) & $1(2)$ \\
\hline Discharged directly home, n (\%) & $36(71)$ \\
\hline Discharged to aftercare facility, n (\%) & $15(29)$ \\
\hline
\end{tabular}

performed in an ASC. Emami et $\mathrm{al}^{26}$ compared 32 one- and two-level minimally invasive transforaminal lumbar interbody fusion procedures performed in an ASC to 64 inpatient cases. The authors reported similar improvement in outcomes scores with slightly lower readmission rates for the patients that had surgery at the ASC (3.1\% versus $4.7 \%)$. A similar study by Emami et $\mathrm{al}^{30}$ reported on 35 outpatient minimally invasive transforaminal lumbar interbody fusion patients with a similar $9 \%$ complication rate and no hospital admissions ${ }^{1}$. Smith et $\mathrm{al}^{28}$ observed a hospital admission rate of $3.7 \%$ in their series of 54 lateral lumbar fusions done in an ASC. Both of the patients that required readmissions were either experiencing urinary retention or needing pain control and did not need reoperation. Chin et $\mathrm{al}^{29}$ reported on a series of 30 single-level lateral lumbar fusions, with no significant complications.

We believe that for anterior lumbar spinal procedures, the BMI of the patient is an important indicator that must be evaluated in conjunction with the body habitus of the patient and overall health status. In the current study, while we did not set a hard upper limit of 30, careful evaluation of all 


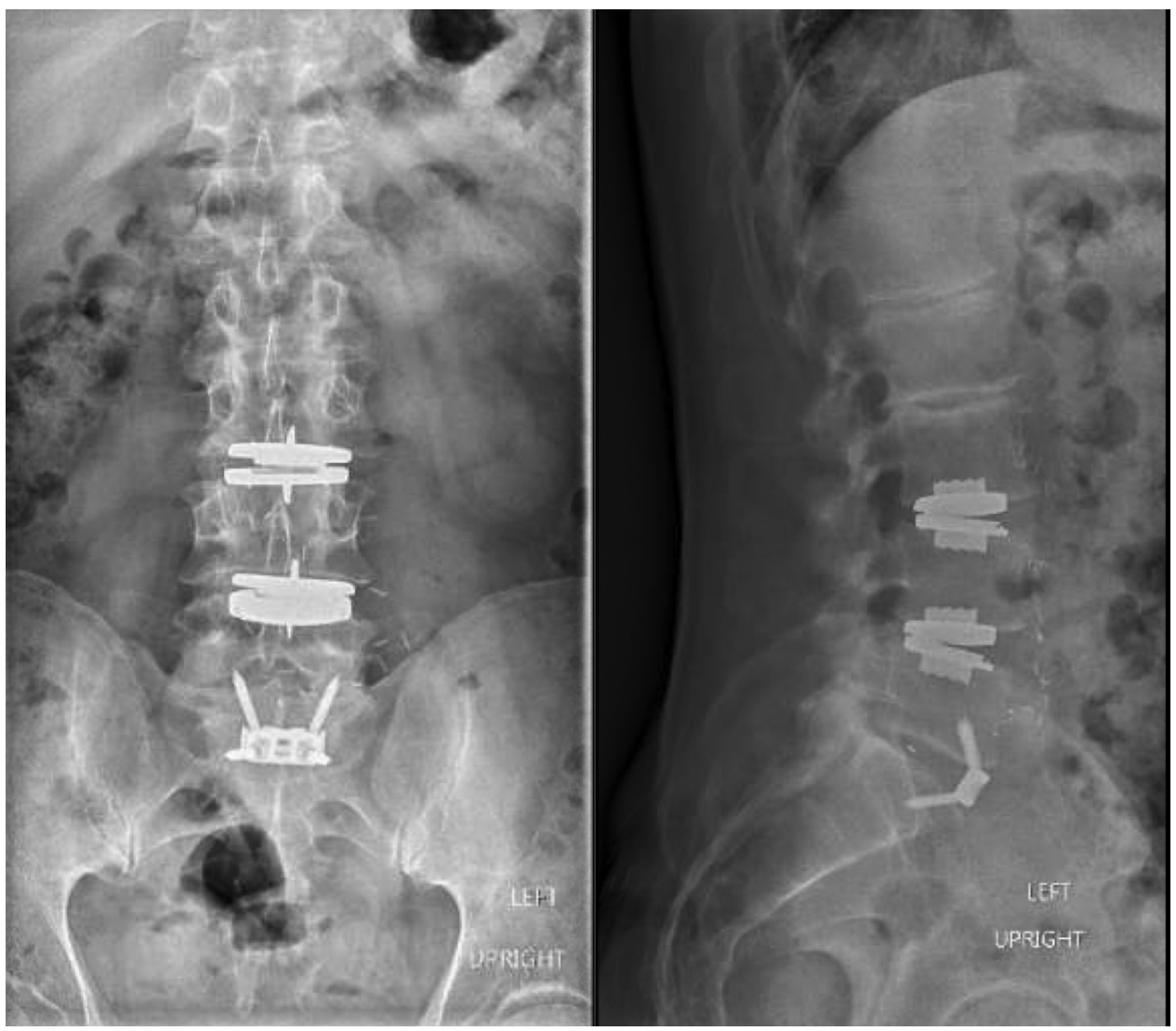

Figure 4. Case example 4. Standing postoperative lumbar spine x-ray of a 54-year-old male following a hybrid procedure at the L3-4, L4-5, and L5-S1 levels performed simultaneously in an ambulatory surgery center.

factors were considered with greater scrutiny in the patients with BMI above 30. Nine of the patients had a BMI of 30 to 33 and 2 had a BMI of 33 to 36. In muscular individuals the BMI can falsely label the patient as obese, and in these cases the physical exam must indicate a lack of abdominal obesity in order to proceed with the operation in an ASC.

The current study has a variety of limitations, one of which was a small study size. Another limitation is the potential inability to extrapolate these findings to spine surgeons in practices without experienced vascular access surgeons. While all patients had follow-up in our offices and a complete chart review was performed, it is conceivable that a minor complication was not reported by the patient to the surgeon and thus went undetected.

In this case series of consecutive patients over a one-year period the authors performed ADR or ALIF at 63 levels in 51 patients in the ASC setting with an observed complication and 30-day hospital admission rate of $1 / 51(2 \%)$. The authors believe these procedures are safe to perform in the ASC setting. However, a highly experienced vascular surgeon and efficient surgical team, with strict patient selection criteria, are all critical in making this possible.

\section{ACKNOWLEDGMENTS}

Khristoffer Thordarson contributed to data collection.

\section{REFERENCES}

1. Adamson T, Godil SS, Mehrlich M, et al. Anterior cervical discectomy and fusion in the outpatient ambulatory surgery setting compared with the inpatient hospital setting: analysis of 1000 consecutive cases. J Neurosurg. 2016;24:878884.

2. Silvers HR, Lewis PJ, Suddaby LS, et al. Day surgery for cervical microdiscectomy: is it safe and effective? J Spinal Disord. 1996;9:287-293.

3. Garringer SM, Sasso RC. Safety of anterior cervical discectomy and fusion performed as outpatient surgery. $J$ Spinal Disord Tech. 2010;23:439-443.

4. Fu MC, Gruskay JA, Samuel AM, et al. Outpatient anterior cervical discectomy and fusion is associated with fewer short-term complications in one- and two-level cases: a propensity-adjusted analysis. Spine (Phila Pa 1976). 2017;42:1044-1049. 
5. Liu JT, Briner RP, Friedman JA. Comparison of inpatient vs. outpatient anterior cervical discectomy and fusion: a retrospective case series. BMC Surg. 2009;9:3.

6. Lied B, Ronning PA, Halvorsen CM, et al. Outpatient anterior cervical discectomy and fusion for cervical disk disease: a prospective consecutive series of 96 patients. Acta Neurol Scand. 2013;127:31-37.

7. Khanna R, Kim RB, Lam SK, et al. Comparing shortterm complications of inpatient versus outpatient single-level anterior cervical discectomy and fusion: an analysis of 6940 patients using the ACS-NSQIP database. Clin Spine Surg. 2018;31:43-47.

8. McClelland S 3rd, Oren JH, Protopsaltis TS, et al. Outpatient anterior cervical discectomy and fusion: a metaanalysis. J Clin Neurosci. 2016;34:166-168.

9. McClelland S 3rd, Passias PG, Errico TJ, et al. Inpatient versus outpatient anterior cervical discectomy and fusion: a perioperative complication analysis of 259,414 patients from the Healthcare Cost and Utilization Project databases. Int J Spine Surg. 2017;11:11.

10. McClelland S 3rd, Passias PG, Errico TJ, et al. Outpatient anterior cervical discectomy and fusion: an analysis of readmissions from the New Jersey State Ambulatory Services database. Int J Spine Surg. 2017;11:3.

11. Sheperd CS, Young WF. Instrumented outpatient anterior cervical discectomy and fusion: is it safe? Int Surg. 2012;97:86-89.

12. Purger DA, Pendharkar AV, Ho AL, et al. Outpatient vs inpatient anterior cervical discectomy and fusion: a populationlevel analysis of outcomes and cost. Neurosurgery. 2018;82:454464.

13. Walid MS, Robinson JS 3rd, Robinson ER, et al. Comparison of outpatient and inpatient spine surgery patients with regards to obesity, comorbidities and readmission for infection. J Clin Neurosci. 2010;17:1497-1498.

14. Trahan J, Abramova MV, Richter EO, et al. Feasibility of anterior cervical discectomy and fusion as an outpatient procedure. World Neurosurg. 2011;75:145-148; discussion 4344.

15. Holly LT, Moftakhar P, Khoo LT, et al. Minimally invasive 2-level posterior cervical foraminotomy: preliminary clinical results. J Spinal Disord Tech 2007;20:20-24.

16. Branch BC, Hilton DL Jr, Watts C. Minimally invasive tubular access for posterior cervical foraminotomy. Surg Neurol Int. 2015;6:81.

17. Wohns R. Safety and cost-effectiveness of outpatient cervical disc arthroplasty. Surg Neurol Int. 2010;1:77.

18. Chin KR, Pencle FJR, Seale JA, et al. Clinical outcomes of outpatient cervical total disc replacement compared with outpatient anterior cervical discectomy and fusion. Spine (Phila Pa 1976). 2017;42:E567-E74.

19. Best NM, Sasso RC. Success and safety in outpatient microlumbar discectomy. J Spinal Disord Tech. 2006;19:334337.

20. Best NM, Sasso RC. Outpatient lumbar spine decompression in 233 patients 65 years of age or older. Spine (Phila Pa 1976). 2007;32:1135-1139; discussion 40.
21. Debono B, Bousquet P, Sabatier P, et al. Postoperative monitoring with a mobile application after ambulatory lumbar discectomy: an effective tool for spine surgeons. Eur Spine J. 2016;25:3536-3542.

22. Debono B, Sabatier P, Garnault V, et al. Outpatient lumbar microdiscectomy in France: from an economic imperative to a clinical standard-an observational study of 201 cases. World Neurosurg. 2017;106:891-897.

23. An HS, Simpson JM, Stein R. Outpatient laminotomy and discectomy. J Spinal Disord. 1999;12:192-196.

24. Singhal A, Bernstein M. Outpatient lumbar microdiscectomy: a prospective study in 122 patients. Can J Neurol Sci. 2002;29:249-252.

25. Helseth O, Lied B, Halvorsen CM, et al. Outpatient cervical and lumbar spine surgery is feasible and safe: a consecutive single center series of 1449 patients. Neurosurgery. 2015;76:728-737; discussion 37-38.

26. Emami A, Faloon M, Issa K, et al. Minimally invasive transforaminal lumbar interbody fusion in the outpatient setting. Orthopedics. 2016;39:e1218-e1222.

27. Villavicencio AT, Nelson EL, Mason A, et al. Preliminary results on feasibility of outpatient instrumented transforaminal lumbar interbody fusion. J Spinal Disord Tech. 2013;26:298-304.

28. Smith WD, Wohns RN, Christian G, et al. Outpatient minimally invasive lumbar interbody: fusion predictive factors and clinical results. Spine (Phila Pa 1976). 2016;41(Suppl 8):S106-S122.

29. Chin KR, Pencle FJ, Coombs AV, et al. Lateral lumbar interbody fusion in ambulatory surgery centers: patient selection and outcome measures compared with an inhospital cohort. Spine (Phila Pa 1976). 2016;41:686-692.

30. Emami AP, Sina \& Shafa, Eiman \& Patel, Sujal \& Sinha, Kumar \& Issa, Kimona \& Faloon, Michael \& Hwang, Ki. Can Minimally Invasive Transforminal Lumbar Interbody Fusions Be Safely Performed as an Outpatient Procedure? The Spine Journal 2014;14:165.

Disclosures and COI: The authors have not received funding related to this study and report no conflicts of interest.

Corresponding Author: Jason M. Cuellar, MD, PhD, $450 \mathrm{~N}$ Roxbury Drive, 3rd Floor, Beverly Hills, CA 90210. Phone: (310) 385-7766; Email: cuellarj@gmail.com.

Published 11 November 2020

This manuscript is generously published free of charge by ISASS, the International Society for the Advancement of Spine Surgery. Copyright (C) 2020 ISASS. To see more or order reprints or permissions, see http://ijssurgery.com. 